\title{
Design of Fuzzy Membership Functions for Predicting Student's Knowledge Performance
}

\author{
Salisu Muhammad Sani
}

\begin{abstract}
A Fuzzy logic controller is a problem-solving control system that provides means for representing approximate knowledge. The output of a fuzzy controller is derived from the fuzzifications of crisp (numerical) inputs using associated membership functions. The crisp inputs are usually converted to the different members of the associated linguistic variables based on their respective values. This point is evident enough to show that the output of a fuzzy logic controller is heavily dependent on its memberships of the different membership functions, which can be considered as a range of inputs [4]. Input membership functions can take various forms trapezoids, triangles, bell curves, singleton or any other shape that accurately enables the distribution of information within the system, in as much as the shape provides a region of transition between adjacent membership functions.
\end{abstract}

Index Terms-Fuzzy Logic Controller, Fuzzy Membership Function, Student Model, ITS.

\section{INTRODUCTION}

Fuzzy logic was introduced by Lotfi A. Zadeh of University California at Berkeley to provides a definitive solution to problems of information that may be construed as uncertain or imprecise [1]. It deals with reasoning that is approximate rather than fixed and exact. In other words, the concept of fuzzy logic enables reasoning and making rational decisions in circumstances of imprecision, uncertainty, human subjectivity, incomplete information and deficient computations. The basic element of the fuzzy logic theory is the fuzzy set. A fuzzy set describes a characteristic, thing, fact or state. For example, "novice" is a fuzzy set that describes knowledge level, "young" is a fuzzy set that describes age, "cold" is a fuzzy set that describes a body temperature, "tall" is a fuzzy set that describes height, "loud" is a fuzzy set that describes sound's intensity, "close" is a fuzzy set that describes the distance between two objects [2].

\section{RELATED LiterATURE}

\section{A. Overview of Membership Functions}

A fuzzy set A of a universe of discourse $\mathrm{X}$ (the range over which the variables span) is characterized by a membership function $\mu_{\mathrm{A}}(\mathrm{x}): \mathrm{X} \rightarrow[0 ; 1]$ which associates with each element $\mathrm{x}$ of $\mathrm{X}$ a number $\mu_{\mathrm{A}}(\mathrm{x})$ in the interval $[0,1]$, with

Published on November 9, 2019.

S. M. Sani is with the Department of Mathematics and Computer Science, Sule Lamido University, Kafin Hausa, Nigeria. (e-mail: salisum.sani@jsu.edu.ng)
$\mu_{\mathrm{A}}(\mathrm{x})$ representing the degree of membership of $\mathrm{x}$ in A [5]. The membership function, often given the symbol $\mu$, is the basis of fuzzy set theories. It is a curve that defines how each point in the input space (the crisp input) is mapped to a to a fuzzy term and a corresponding degree of membership usually taken as a real number in the interval $[0,1]$. The crisp inputs are mapped into the membership functions on the antecedent part defined by fuzzy rules to obtain the corresponding fuzzy terms or linguistic variables and a corresponding degree of membership for each linguistic variable. The use of membership function in fuzzification process has created more alternatives to assign membership values to fuzzy terms than there are to assign probability density values to random variables [6]. Membership functions are subjective and context-dependent that means that it is hard for a system to automatically generate them in a concrete and formal way. The choice of membership functions is a key problem in the design of a fuzzy controller and therefore the way to select them usually determined by experts, based on its suitability such as simplicity, convenience, speed, and efficiency [7]. The membership functions can take one of the symmetric or asymmetric forms of triangles, exponential Gauss, trapezoid and so on in the general unified form. The peculiarity of a fuzzy set is that objects belong to the set with a certain degree, called membership value. This value is a continuous number ranging from 0 (complete exclusion) to 1 (complete membership) [8]. A fuzzy set A can be uniquely defined by a membership function of the form:

$$
\mu_{\mathrm{A}}: U \rightarrow[0,1]
$$

$\mathrm{U}$ is called the domain, space, or universe of discourse. For each $\mathrm{x} \in \mathrm{U}$, the value $\mu \mathrm{A}(\mathrm{x})$ expresses the membership degree of $x$ in the fuzzy set A. It can be observed that such a definition of fuzzy set extends the traditional definition of set theory or probability density, in which the membership degree of the objects can respectively assume only two values belong or not belong and true or false. In principle, any kind of function of the form: $\mu_{\mathrm{A}}: U \rightarrow[0,1]$ can be used to represent a membership function. However, some basic functions are commonly used in the literature such as piece-wise linear functions formed using straight lines such as triangular, trapezoidal, Gaussian distribution function. In this thesis, all membership functions have a trapezoidal form, because experimental data showed that this choice enhances the ability of determining the correct user situation. The following are example of types of membership functions: 


\section{B. Triangular Membership Function}

The triangular membership function also known as trimf [9] is a collection of three points forming a triangle. This type of membership function is defined by a lower bound $\mathbf{a}$, an upper bound $\mathbf{b}$, and a value $\mathbf{m}$, such that $\mathbf{a}<\mathbf{m}<\mathbf{b}$.

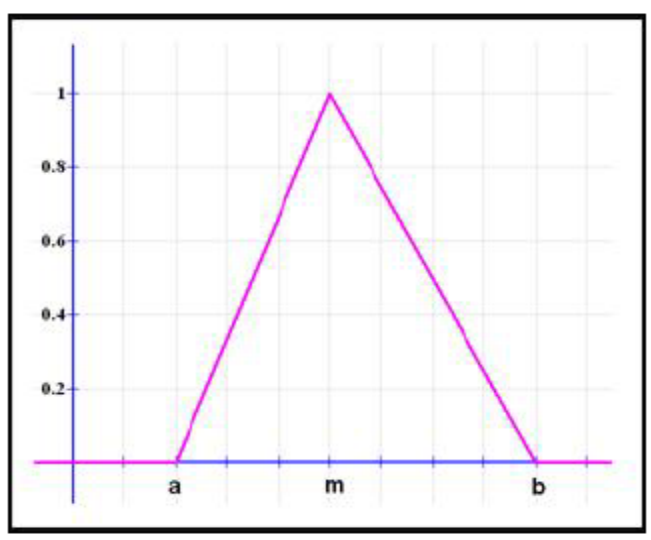

Fig. 1. Triangular Membership Function

\section{Trapezoidal Membership Function}

The trapezoidal membership function, trapmf, has a flat top and really is just a truncated triangle curve [10]. These straight line membership functions have the advantage of simplicity. This type of membership function is defined by a lower limit $\mathbf{a}$, an upper limit $\mathbf{d}$, a lower support limit $\mathbf{b}$, and an upper support limit $\mathbf{c}$, where $\mathbf{a}<\mathbf{b}<\mathbf{c}<\mathbf{d}$

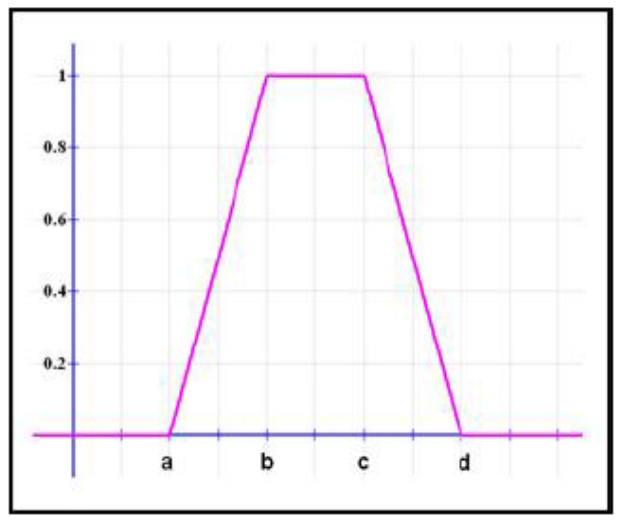

Fig. 2. Trapezoidal Membership Function

\section{Gaussian Membership Function}

The Gaussian membership function is defined by a central value $\mathbf{m}$ and a standard deviation $\mathbf{k}>\mathbf{0}$. The smaller $\mathrm{k}$ is, the narrower the "bell" is.

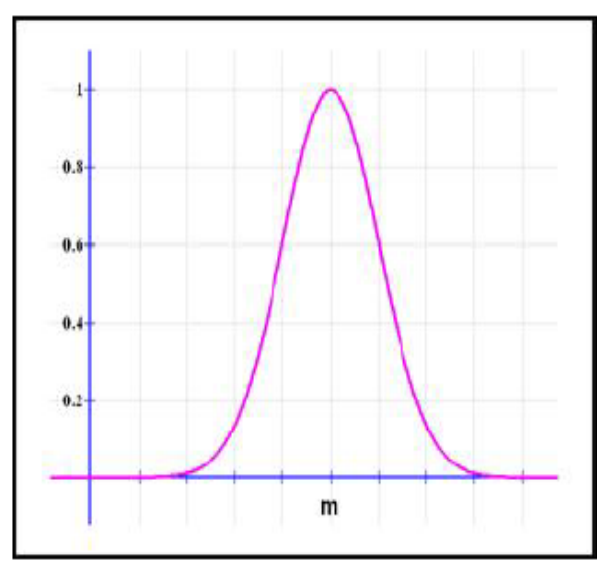

Fig. 3. Gaussian Membership Function

\section{E. Operations on Membership Functions}

The most common fuzzy operators are intersection operation and union operation. To formulate these logical operation, function min and function max are applied. Although other functions, such as compliment, are also applicable in expressing these fuzzy operators, functions min and function max are always simple, effective and widely used [11].

Given two sets $A$ and $B$, the membership functions $\mu_{A}(x)$ and $\mu_{\mathrm{B}}(\mathrm{x})$ which can be represented graphically in Fig. 4 and 5 respectively.

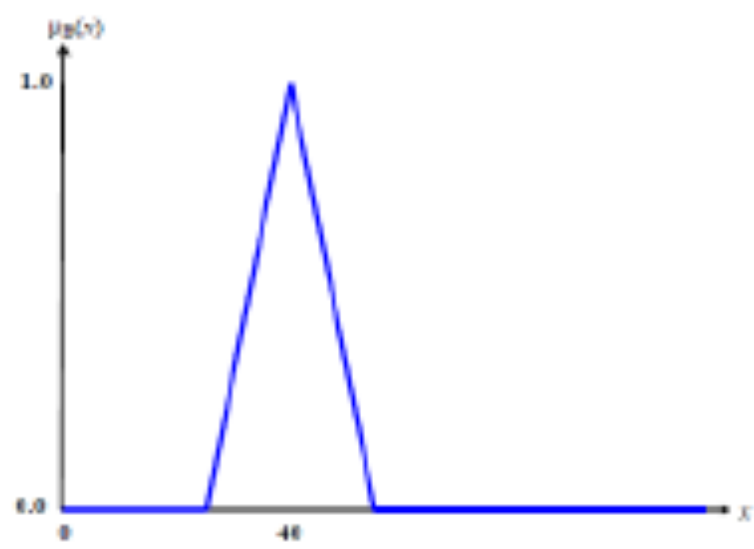

Fig. 4. Fuzzy Set A

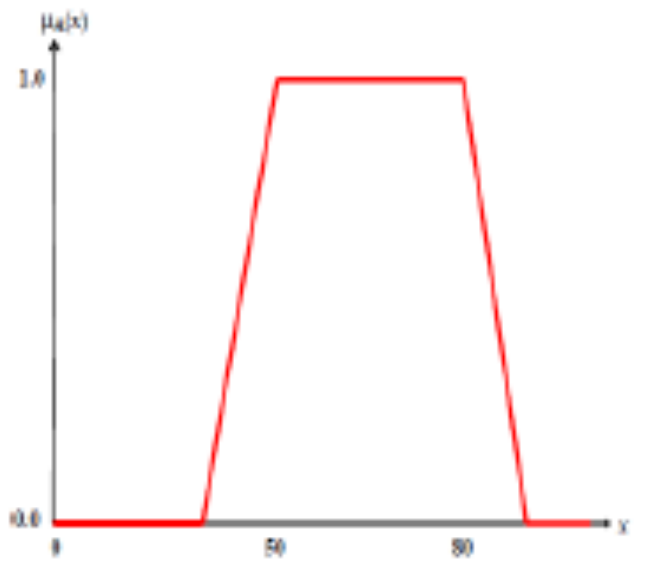

Fig. 5. Fuzzy Set B 
1) Intersection

The intersection of two fuzzy sets A and B is defined as:

$\mu(\mathrm{A} \cap \mathrm{B})(\mathrm{x})=\min (\mu \mathrm{A}(\mathrm{x}), \mu \mathrm{B}(\mathrm{x}))$

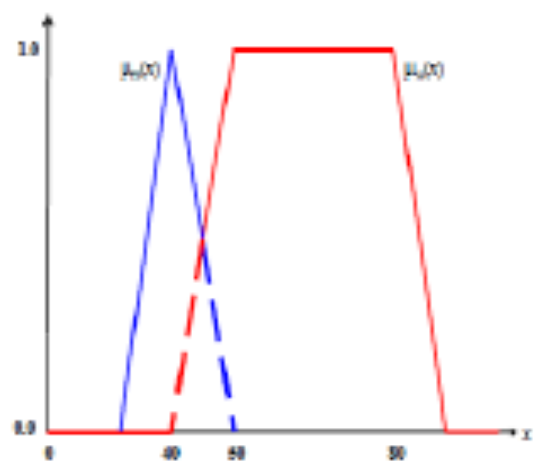

Fig. 6. Intersection of Fuzzy Sets A and B

\section{2) Union}

The union of two fuzzy sets A and B is defined as:

$$
\mu(\mathrm{AUB})(\mathrm{x})=\max (\mu \mathrm{A}(\mathrm{x}), \mu \mathrm{B}(\mathrm{x}))
$$

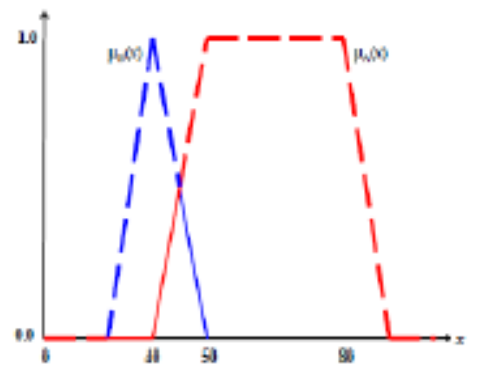

Fig. 7. Union of Fuzzy Sets A and B

\section{3) Compliment}

The compliment of a fuzzy set A denoted as $\bar{A}$ is defined as:

$$
\mu_{\bar{A}(\mathrm{x})}=1-\mu_{\mathrm{A}}(\mathrm{x})
$$

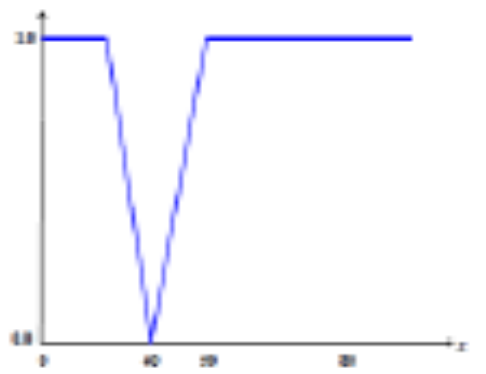

Fig. 8. Compliment of Fuzzy Set A

\section{Methodology}

\section{A. The Proposed Fuzzy Student Model Design}

Intelligent Tutoring Systems (ITSs) are special classes of
E-learning systems designed to provide adaptive and personalized tutoring based on the individuality of students [12]. An important component of an ITS that is responsible for providing the basis for this personalization is called the student model. During the course of interaction between the learner and an ITS, a quantitative representation of the actual student's characteristics such as knowledge state and learning style is created based on the observations and predictions the ITS made on each student. The student's knowledge is one of the most dynamic characteristic; so dynamic like a moving target. However, modeling student's knowledge and diagnosis are complex processes that are characterized by uncertainty and imprecision issues that affect the prediction of the student model in an ITS. Fuzzy logic is a form of multi-valued logic derived from fuzzy set theory. An approximate student model based on fuzzy membership function approach enables making accurate predictions about the state of student's knowledge.

Student modeling is a vital process in ITS where the tutoring system observes students' actions and creates quantitative representations of each learner's properties of interest, which are vital to other ITS modules. The main goal of a student model is to support making instructional decisions based on the individuality of the learners. A good student model that matches student behaviors to student properties of interest can often provide insightful information to both the system and the researchers. Student behaviors can be viewed as the input of a student model, which include a variety of observations, such as student responses and actions. Student's characteristics of interest represent what the student is being modeled.

Depending on the requirements, the range of things being modeled could be fairly broad: student knowledge, student performance, student emotions, learning styles and other constructs of interest. Student models create quantitative representations, which are consumable to other modules within the ITS, and most of which are also interpretable to humans outside the system. It has been said that a welldesigned tutoring system actively undertakes two tasks: that of the diagnostician, discovering the nature and extent of the student's behavioral attitudes such as knowledge, and that of the strategist planning, a response using its findings about the learner (Jeremić, Jovanović \& Gašević, 2012). This is the main role of student model, which is the base for personalization in intelligent tutoring systems [14].

The information of a student model is used by the system in order to adapt its responses to each individual student dynamically providing personalized instruction, help and feedback. The student model is used for accurate diagnosis in order to predict students' needs and adapt the learning materials and processes to each individual student's learning pace. Moreover, by predicting of student affective state, an adaptive and/or personalized educational system can select appropriate learning methods in order to increase the effectiveness of tutorial interactions and improve the learning and motivation. In addition, a student model can be used for identifying the student's strength and weaknesses in order to provide him/her with customized or individualized feedback [15].

The ability of the ITS to adapt to each student's needs in terms of content presentation of various topics in a domain 
knowledge (DK) to students with different characteristics, assess and provides interactive feedback to each individual student is one of its huge advantage over the traditional elearning systems. Thus knowledge is the key to modeling intelligent behavior and this means an ITS is characterized by the following basic knowledge; first, the domain knowledge, secondly, knowledge of the tutoring principles and the approaches to carry them out and thirdly, knowledge of how model the knowledge and skills acquired by the learners.

One major limitation of testing student knowledge using the traditional computer assisted paradigms is the necessity for manually defining huge amount of questions of various difficulty levels by the tutor. Instead, it will be far better to let an intelligent adaptive tutoring system independently to dynamically generate questions and conduct an adaptive tests based on the concepts in the domain knowledge (DK). For the benefit of securing the training data for this research, such type of knowledge testing is adopted in adaptive course ware (AC-ware) tutor model [16]. In order to test student knowledge on courseware elements in the AC-ware system, questions are generated from the subset of domain knowledge. This subset of domain testing provides the input for knowledge testing on a student and the domain knowledge also corresponds to a union of courseware learning elements before the actual testing in the $\mathrm{AC}$-ware model.

Two weighted functions $X_{A}$, the score obtained by answering a question that applies to edge and $\mathrm{X}_{\mathrm{V}}$, corresponds to the membership degree value of a student knowing concept $\mathrm{Kx}$. The values of the function $\mathrm{X}_{\mathrm{V}}$ are determined after each knowledge test and calculation of its values depend on the question score and its corresponding membership degree value. The output of knowledge test also known as the weighted sum of values $\mathrm{X}_{\mathrm{A}}(\mathrm{Kx})$ enables this research to adopt student models according to knowledge level Table I [16].

TABLE I: RANGE OF KNOWLEDGE LEVELS

\begin{tabular}{lll}
\hline $\begin{array}{l}\text { Student } \\
\text { Model }\end{array}$ & $\mathrm{Xv}$ Values Interval & $\begin{array}{l}\text { Knowledge } \\
\text { Level }\end{array}$ \\
\hline Novice & $\mathrm{X}_{\mathrm{A}}(\mathrm{Kx}) \leq 0.2$ & $\mathrm{~L}=0$ \\
\hline Beginner & $0.2 \leq \mathrm{X}_{\mathrm{A}}(\mathrm{Kx}) \leq 0.4$ & $\mathrm{~L}=1$ \\
\hline intermediate & $0.4 \leq \mathrm{X}_{\mathrm{A}}(\mathrm{Kx}) \leq 0.6$ & $\mathrm{~L}=2$ \\
\hline Advance & $0.6 \leq \mathrm{X}_{\mathrm{A}}(\mathrm{Kx}) \leq 0.8$ & $\mathrm{~L}=3$ \\
\hline Expert & $0.8 \leq \mathrm{X}_{\mathrm{A}}(\mathrm{Kx}) \leq 1$ & $\mathrm{~L}=4$ \\
\hline \hline
\end{tabular}

To generates questions based on lower difficulty category $\mathrm{L}$ (except at $\mathrm{L}=0$ ), where questions that the student answered incorrectly on concepts became the input (since at the difficulty category 0 bears no questions). However, the questions on concepts that the student answered correctly become the inputs for generating questions from higher level category $\mathrm{L}+2(\mathrm{~L}=3$ and $\mathrm{L}=4$ inclusive). This continues until there are no more questions that can be generated.

\section{B. Definition 1}

Let the set of domain concepts denoted as $\mathrm{K}=\left\{\mathrm{K}_{1}, ., \mathrm{Kx}\right\}$, $x \geq 0$, be a set of concepts, and let a set of relation $R=\left\{R_{1}\right.$, . .., $\mathrm{Rn}\} \mathrm{U}\{$ has_superset, has_subset, has_instance $\}, \mathrm{n} \geq 0$, be a set of relations and $\varnothing^{-}$an empty set element. This definition enables domain knowledge DK to be a set of triplets $\left(\mathrm{K}_{1}, \mathrm{R}, \mathrm{K}_{2}\right)$ that shows how concepts $\mathrm{K}_{1}$ and $\mathrm{K}_{2}$ are associated with relation $\mathrm{R}$. In this way we define that the concept $\mathrm{K}_{1}$ is the superset of concept $\mathrm{K}_{2}$ and that concept $\mathrm{K}_{2}$ is the subset of concept $\mathrm{K}_{1}$.

\section{Definition 2}

The membership function is defined in terms of an ordered pair domain knowledge graph $(\mathrm{DKG})=(\mathrm{V}, \mathrm{E})$ where $\mathrm{V}$ is a set of vertices defined by $\left(\mathrm{Kx}, \mathrm{X}_{\mathrm{A}}\right)$ and $\mathrm{E}$ is a set of edges where $E=\left\{K_{1}, K_{2}\right\}:\left(K_{1}, R, K_{2}\right) \in D K$ is equal to a set of ordered pairs of those concepts from the domain knowledge that are related.

TABLE II: PART OF TRAINING DATA

\begin{tabular}{ll}
\hline \hline Doman Concept $(\mathrm{Kx})$ & Score XA(KX) \\
\hline 1.44MB & 0.125 \\
\hline Addition & 0 \\
\hline AND gate & 0 \\
\hline Application Software & 0.375 \\
\hline Arithmetic Logic Unit & 0.375 \\
\hline Arithmetic Operations & 0 \\
\hline Assembler & 0 \\
\hline Basic & 0 \\
\hline Basic Computer Function & 0.7917 \\
\hline C & 0.25 \\
\hline Capacity & 0.125 \\
\hline Central Processing Unit & 0.5 \\
\hline Compact Disk & 0.25 \\
\hline Compiler & 0 \\
\hline Computer & 0.5 \\
\hline Computer System & 0.33 \\
\hline Conjunction & 0 \\
\hline Control Unit & 0.5 \\
\hline Data & 0.25 \\
\hline \hline
\end{tabular}

\section{Membership Functions Design}

Designing the proposed input/output membership functions, the fuzzifeir is heuristic and the first step of the fuzzy logic control process. The input/output membership functions are primarily designed to transform the crisp (numerical) data entering the system by assigning linguistic variables and their corresponding membership degrees to the terms in those categories. Moreover, it is known that there are no defined criteria for designing or selecting which shape the membership function can take, instead, it is a matter of judgment of the expert designer to choose from either triangular, trapezoidals, bell curves or any other shape as long as those shapes accurately represent the distribution of information within the system, and as long as a region of transition exists between adjacent membership functions [4]. This research proposed both heuristic and data-based models for the membership functions design. The importance of the heuristic method is to emphasize that membership functions design is subjective to designer's expertise and considerations as this will help in reducing single expert dependency.

Because of its flexibility and linearity, this study proposes the design of trapezoidal-based membership functions for six fuzzy sets "poor", "weak", "average", "good", "very good" and "excellent" to enable the first fuzzy control process, the fuzzification process to model a trapezium area that has a universe of discourse ranging from 0 to 1 . The proposed trapezoid membership functions are specified by four points $\{a, b, c, d\}$ with each point being represented in the $\mathrm{x}-\mathrm{y}$ plane by its co-ordinates $\left(\mathrm{x}_{\mathrm{i}}, \mathrm{y}_{\mathrm{i}}\right)$. This enables the procedure for defining the six regions for each trapezoidal 
fuzzy set based on its distinct co-ordinates (Table III).

TABLE III: MEMBERSHIP FUNCTION CO-ORDINATES FOR ALL SIX FUZZY SETS

\begin{tabular}{ll}
\hline \hline Fuzzy Set & Membership Function Coordinates \\
\hline Poor & {$\left[\left(\mathrm{x}_{1}, \mathrm{y}_{1}\right),\left(\mathrm{x}_{2}, \mathrm{y}_{2}\right),\left(\mathrm{x}_{3}, \mathrm{y}_{3}\right),\left(\mathrm{x}_{4}, \mathrm{y}_{4}\right)\right]$} \\
\hline Weak & {$\left[\left(\mathrm{x}_{5}, \mathrm{y}_{5}\right),\left(\mathrm{x}_{6}, \mathrm{y}_{6}\right),\left(\mathrm{x}_{7}, \mathrm{y}_{7}\right),\left(\mathrm{x}_{8}, \mathrm{y}_{8}\right)\right]$} \\
\hline Average & {$\left[\left(\mathrm{x}_{9}, \mathrm{y}_{9}\right),\left(\mathrm{x}_{10}, \mathrm{y}_{10}\right),\left(\mathrm{x}_{11}, \mathrm{y}_{11}\right),\left(\mathrm{x}_{12}, \mathrm{y}_{12}\right)\right]$} \\
\hline Good & {$\left[\left(\mathrm{x}_{13}, \mathrm{y}_{13}\right),\left(\mathrm{x}_{14}, \mathrm{y}_{14}\right),\left(\mathrm{x}_{15}, \mathrm{y}_{15}\right),\left(\mathrm{x}_{16}, \mathrm{y}_{16}\right)\right]$} \\
\hline V. Good & {$\left[\left(\mathrm{x}_{17}, \mathrm{y}_{17}\right),\left(\mathrm{x}_{18}, \mathrm{y}_{18}\right),\left(\mathrm{x}_{19}, \mathrm{y}_{19}\right),\left(\mathrm{x}_{20}, \mathrm{y}_{20}\right)\right]$} \\
\hline Excellent & {$\left[\left(\mathrm{x}_{21}, \mathrm{y}_{21}\right),\left(\mathrm{x}_{22}, \mathrm{y}_{22}\right),\left(\mathrm{x}_{23}, \mathrm{y}_{23}\right),\left(\mathrm{x}_{24}, \mathrm{y}_{24}\right)\right]$} \\
\hline \hline
\end{tabular}

The $\mathrm{x}_{\mathrm{i}}$ 's represents the student's score in a domain concept $\left(0 \leq x_{i} \leq 1\right)$ from the universe of discourse and the $y_{i}$ 's represents the two ends of the intervals $[0,1]\left(\mathrm{y}_{\mathrm{i}}=0\right.$ or $\left.\mathrm{y}_{\mathrm{i}}=1\right)$ for membership degrees.

\section{E. Criteria for Tuning the Membership Functions}

It has been established in the literature that there is no defined criteria for obtaining standard tuning for the optimum values of fuzzy membership functions, because every optimum value for tuning membership function depends on the type of model and its control objective, so tuning fuzzy membership functions must be done based on the experts' knowledge of the controlled environment not by computation, thus the study to adopt the following criteria for tuning the coordinates of all the membership functions contained in the three fuzzifiers Fuzzifier_1, Fuzzifier_2 and Fuzzifier 3.

1. The values to be assigned to the $\mathrm{x}_{\mathrm{i}}$ 's in $\left(\mathrm{x}_{\mathrm{i}}, \mathrm{y}_{\mathrm{i}}\right)$ coordinates must be within the universe of discourse $[0,1]$ (Table I). The values of yi's in (xi,yi) co-ordinates must be either the lower or upper bounds of the membership degree in the interval $[0,1]$

2. The four vertices and their corresponding arcs that define the graph of each fuzzy set (Table III) must produce a trapezoidal shape with flat top, the core of the membership function when plotted on the $x-y$ plane

3. A region of transition also known and defined in the literature as intersection region between two adjacent membership functions must exist

4. The membership functions for the three fuzzifiers must be distinct in either core, transition (intersection) region or in their lower or upper bounds

With these criteria, this study has successfully tuned the membership function's coordinates that will enable the design of three novel fuzzifiers Fuzzifier_1, Fuzzifier_2 and Fuzzifier 3.

\section{F. Tuning the six trapezoidal membership functions graphs for fuzzifier_1}

To tune the co-ordinates that will be plotted to generates the membership functions graph for fuzzifier_1, specific values of $\mathrm{x}_{\mathrm{i}}$ 's and $\mathrm{y}_{\mathrm{i}}$ 's respectively from the universe of discourse, the student scores (Table I) and lower or upper bounds of the membership degrees' interval [0,1], will be selected heuristically based on the propose criteria to define the co-ordinates of the six trapezoidal membership functions graphs for fizzifier_1.

Table IV described the tuned co-ordinates for all four vertices in fuzzifier_1. Here, the co-ordinates of each trapezoidal membership function representing the six fuzzy sets are now assigned specific values. Plotting these coordinates on $\mathrm{x}-\mathrm{y}$ plane generates the graph of the fuzzifier_1 (Fig. 9).

\begin{tabular}{ll} 
& TABLE IV: Co-ORDINATES FOR FUZZIFIER 1 \\
\hline \hline Fuzzy Set & Tuned Co-ordinates \\
\hline Poor & {$[(0,0),(0,1),(0.05,1),(0.1,0)]$} \\
\hline Weak & {$[(0.05,0),(0.15,1),(0.25,1),(0.3,0)]$} \\
\hline Average & {$[(0.25,0),(0.35,1),(0.45,1),(0.5,0)]$} \\
\hline Good & {$[(0.45,0),(0.55,1),(0.65,1),(0.7,0)]$} \\
\hline V. Good & {$[(0.65,0),(0.75,1),(0.85,1),(0.9,0)]$} \\
\hline Excellent & {$[(0.85,0),(0.95,1),(1,1)]$} \\
\hline \hline
\end{tabular}

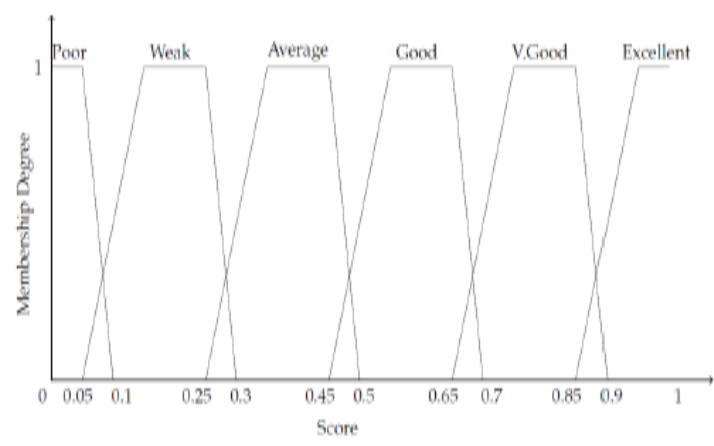

Fig. 9. Membership Function Graph for Fuzzifier_1

\section{G. Tuning the six trapezoidal membership functions graphs for fuzzifier_2}

To tune the co-ordinates that will be plotted to generates the membership functions graph for fuzzifier_2, specific values of $\mathrm{Xi}_{\mathrm{i}}$ 's and $\mathrm{y}_{\mathrm{i}}$ 's respectively from the universe of discourse, the student scores (Table I) and lower or upper bounds of the membership degrees' interval [0,1], will be selected heuristically based on the propose criteria to define the co-ordinates of the six trapezoidal membership functions graphs for fizzifier_2.

Table $\mathrm{V}$ described the tuned co-ordinates for all four vertices in fuzzifier 2. Here, the co-ordinates of each trapezoidal membership function representing the six fuzzy sets are now assigned specific values. Plotting these coordinates on $\mathrm{x}-\mathrm{y}$ plane generates the graph of the fuzzifier 2 (Fig. 10).

TABLE V: CO-ORDINATES FOR FUZZIFIER 2

\begin{tabular}{ll}
\hline \hline Fuzzy Set & Tuned Co-ordinates \\
\hline Poor & {$[(0,0),(0,1),(0.05,1),(0.15,0)]$} \\
\hline Weak & {$[(0.05,0),(0.15,1),(0.25,1),(0.35,0)]$} \\
\hline Average & {$[(0.25,0),(0.35,1),(0.45,1),(0.55,0)]$} \\
\hline Good & {$[(0.45,0),(0.55,1),(0.65,1),(0.75,0)]$} \\
\hline V. Good & {$[(0.65,0),(0.75,1),(0.85,1),(0.95,0)]$} \\
\hline Excellent & {$[(0.85,0),(0.95,1),(1,1)]$} \\
\hline \hline
\end{tabular}




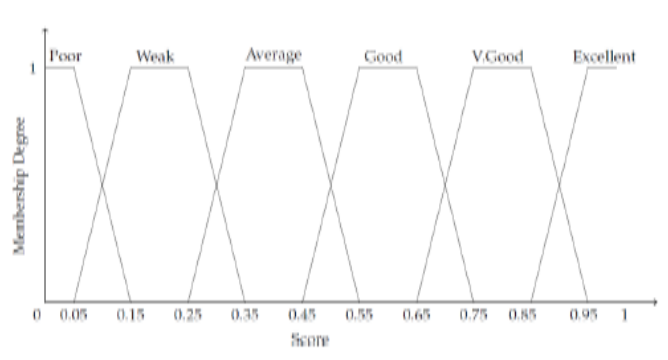

Fig. 10. Membership Function Graph for Fuzzifier_2

\section{H. Tuning the six trapezoidal membership functions graphs for fuzzifier_3}

To tune the co-ordinates that will be plotted to generates the membership functions graph for fuzzifier 3, specific values of $\mathrm{x}_{\mathrm{i}}$ 's and $\mathrm{y}_{\mathrm{i}}$ 's respectively from the universe of discourse, the student scores (Table I) and lower or upper bounds of the membership degrees' interval [0,1], will be selected heuristically based on the propose criteria to define the co-ordinates of the six trapezoidal membership functions graphs for fizzifier_3.

Table VI described the tuned co-ordinates for all four vertices in fuzzifier_3. Here, the co-ordinates of each trapezoidal membership function representing the six fuzzy sets are now assigned specific values. Plotting these coordinates on $\mathrm{x}-\mathrm{y}$ plane generates the graph of the fuzzifier_3 (Fig. 3).

TABLE VI: CO-ORDINATES FOR FUZZIFIER 3

\begin{tabular}{ll}
\hline \hline Fuzzy Set & Tuned Co-ordinates \\
\hline Poor & {$[(0,0),(0,1),(0.05,1),(0.1,0)]$} \\
\hline Weak & {$[(0.08,0),(0.15,1),(0.25,1),(0.3,0)]$} \\
\hline Average & {$[(0.28,0),(0.35,1),(0.45,1),(0.5,0)]$} \\
\hline Good & {$[(0.48,0),(0.55,1),(0.65,1),(0.7,0)]$} \\
\hline V. Good & {$[(0.68,0),(0.75,1),(0.85,1),(0.9,0)]$} \\
\hline Excellent & {$[(0.88,0),(0.95,1),(1,1)]$} \\
\hline \hline
\end{tabular}

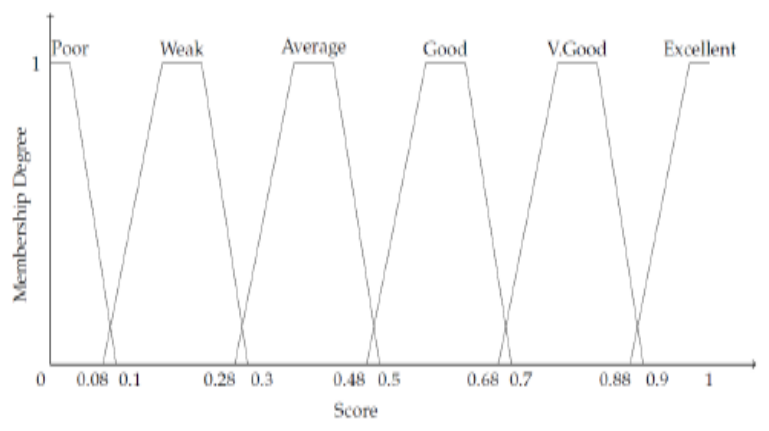

Fig. 11. Membership Function Graph for Fuzzifier_3

\section{CONCLUSION}

This study has successfully designed three novel fuzzy based membership functions control process which model and predict student's knowledge performances as in fuzzifier_1, fuzzifier_2 and fuzzifier_3 using six linguistic variables poor, weak, average, good, very good and excellent. Successful design of these membership functions, the first and most vital components of any fuzzy logic controller has enables the realization of three fuzzy student models. An approximate student model based on fuzzy membership function approach enables making accurate predictions about the state of student's knowledge which will in turn allow for necessary diagnosis on them. The main goal of desgning the three models is to enables successful realization of the next fuzzy logic control process, the fuzzy inference process to allow for the necessary diagnosis on the propose fuzzy student models.

\section{REFERENCES}

[1] L. A. Zadeh, "Zadeh-1965.pdf," Inf. Control, vol. 8, pp. 388-353, 1965.

[2] K. Chrysafiadi and M. Virvou, "Fuzzy Logic in Student Modeling," in Intelligent Systems Reference Library, vol. 78, 2015, pp. 25-59.

[3] Y. Bai and D. Wang, "Fundamentals of Fuzzy Logic Control - Fuzzy Sets , Fuzzy Rules and Defuzzifications," Adv. Fuzzy Log. Technol. Ind. Appl., pp. 334-351, 2006.

[4] H. Hagras, "Fuzzy Logic Control and Hybrid Systems 'Lecture Notes," vol. 4, no. 3, pp. 1-10, 2013.

[5] H. Hamdan, "An Exploration of the Adaptive Neuro-Fuzzy Inference System ( ANFIS ) in Modelling Survival Thesis submitted to The University of Nottingham for the Degree of Doctor of Philosophy An Exploration of the Adaptive Neuro-Fuzzy Inference System ( ANFIS ) in Mo," 2013.

[6] G. Goel, S. Lallé, and V. Luengo, "Fuzzy Logic Representation for Student Modelling * Case Study on Geometry," vol. 63, no. 4, pp. 428-433, 2011.

[7] M. R. Priya and G. Keerthy, "Rule-Based Fuzzy Logic for Automatic Learning Process in an E-learning Environment," vol. 4, no. 7, pp. 567-571, 2015.

[8] I. Iancu, “A Mamdani Type Fuzzy Logic Controller," Rijeka INTECH Open Access Publ., pp. 325-350, 2012.

[9] O. A. M. Ali, A. Y. Ali, and B. S. Sumait, "Comparison between the Effects of Different Types of Membership Functions on Fuzzy Logic Controller Performance," Int. J. Emerg. Eng. Res. Technol., vol. 3, no. 3, pp. 76-83, 2015.

[10] Y. Gong, "Student Modeling in Intelligent Tutoring Systems," 2014.

[11] C. Wang, "A Study of Membership Functions on Mamdani- Type Fuzzy Inference System for Industrial,” 2015.

[12] S. Ani Grubišic, Stankov and I. Peraic, "Expert Systems with Applications Ontology based approach to Bayesian student model design," vol. 40, pp. 5363-5371, 2013.

[13] J. Z. Jeremic, J. Jovanovic and D. Gaševic, "Expert Systems with Applications Student modeling and assessment in intelligent tutoring of software patterns," vol. 39, pp. 210-222, 2012.

[14] C. Conati, "Bayesian student modeling," in Studies in Computational Intelligence, vol. 308, no. 1, 2010, pp. 281-299.

[15] K. Chrysafiadi and M. Virvou, "Expert Systems with Applications Student modeling approaches: A literature review for the last decade," Expert Syst. Appl., vol. 40, no. 11, pp. 4715-4729, 2013.

[16] A. Grubišić, S. Stankov, and B. Žitko, "Adaptive courseware model for intelligent e-learning systems," in International Conference on Computing, E-Learning and Emerging Technologies (ICCEET 2014), 2014, no. 2 . 